\title{
A Role of the Transient Receptor Potential Domain of Vanilloid Receptor I in Channel Gating
}

\author{
Nuria García-Sanz, ${ }^{1 *}$ Pierluigi Valente, ${ }^{1 *}$ Ana Gomis, ${ }^{2}$ Asia Fernández-Carvajal, ${ }^{1}$ Gregorio Fernández-Ballester, ${ }^{1}$ \\ Felix Viana, ${ }^{2}$ Carlos Belmonte, ${ }^{2}$ and Antonio Ferrer-Montiel ${ }^{1}$ \\ ${ }^{1}$ Instituto de Biología Molecular y Celular and ${ }^{2}$ Instituto de Neurociencias de Alicante, Consejo Superior de Investigaciones Científicas, Universidad Miguel \\ Hernández, 03202 Elche, Alicante, Spain
}

Transient receptor potential vanilloid receptor subtype 1 (TRPV1) is an ionotropic receptor activated by temperature and chemical stimuli. The C-terminal region that is adjacent to the channel gate, recognized as the TRP domain, is a molecular determinant of receptor assembly. However, the role of this intracellular domain in channel function remains elusive. Here, we show that replacement of the TRP domain of TRPV1 with the cognate region of TRPV channels (TRPV2-TRPV6) did not affect receptor assembly and trafficking to the cell surface, although those receptors containing the TRP domain of the distantly related TRPV5 and TRPV6 did not display ion channel activity. Notably, functional chimeras exhibited an impaired sensitivity to the activating stimuli, consistent with a significant contribution of this protein domain to channel function. At variance with TRPV1, voltage-dependent gating of chimeric channels could not be detected in the absence of capsaicin and/or heat. Biophysical analysis of functional chimeras revealed that the TRP domain appears to act as a molecular determinant of the activation energy of channel gating. Together, these findings uncover a role of the TRP domain in intersubunit interactions near the channel gate that contribute to the coupling of stimulus sensing to channel opening.

Key words: channel gating; oligomerization; functional coupling; structure-function nociceptor; sensory transduction; capsaicin

\section{Introduction}

Transient receptor potential (TRP) ion channels are considered molecular gateways in sensory systems, because several of them participate in the transduction of chemical and physical stimuli into an impulse discharge at sensory receptor nerve terminals (Montell, 2005; Ramsey et al., 2006). The TRP vanilloid receptor (TRPV) family is composed of six members, named TRPV1 to TRPV6, which play an important role in peripheral detection of innocuous and noxious stimuli, as well as in intracellular $\mathrm{Ca}^{2+}$ homeostasis. TRPV1 is activated by noxious temperature $\geq 42^{\circ} \mathrm{C}$, vanilloids, acidic $\mathrm{pH}$, and proinflammatory substances (Caterina and Julius, 2001; Scholz and Woolf, 2002; Montell, 2005; Planells-Cases et al., 2005; Dhaka et al., 2006; Ramsey et al., 2006). TRPV2 responds to high noxious heat $\left(\geq 53^{\circ} \mathrm{C}\right.$ ) (Caterina and Julius, 2001). TRPV3 is gated by temperatures $\geq 33^{\circ} \mathrm{C}$ and camphor (Smith et al., 2002; Moqrich et al., 2005; Ramsey et al., 2006), whereas TRPV4 is activated at $\geq 27^{\circ} \mathrm{C}$ and also by osmotic changes and phorbol esters (Guler et al., 2002; Watanabe et al.,

\footnotetext{
Received Jan. 8, 2007; revised Aug. 27, 2007; accepted Sept. 3, 2007.

This work was supported by Spanish Ministry of Education and Science Grants SAF2003-0509 and SAF2006-2580 (A.F.-M.) and BFU2005-03986 (A.G.), the Fundación Ramón Areces (A.F.-M.), and Generalitat Valenciana Grants GV-ACOMP06/202 (A.F.-M.) and GV05/076 (A.G.). We thank Drs. Rosa Planells and Marco Caprini for critically reading this manuscript and Reme Torres for CDNA and cRNA preparation, 00cyte injection, and manipulation. We are indebted to Dr. Davis Julius for the CDNA encoding rat TRPV1, Dr. Michael Schaefer for mouse TRPV3, and Dr. Tim Plant for human TRPV4.

${ }^{*}$ N.G.S. and P.V. contributed equally to this work.

Correspondence should be addressed to Antonio Ferrer-Montiel, Instituto de Biología Molecular y Celular, Universidad Miguel Hernández, Avenida de la Universidad s/n, 03202 Elche, Alicante, Spain. E-mail: aferrer@umh.es. DOl:10.1523/JNEUROSCI.2457-07.2007

Copyright $\odot 2007$ Society for Neuroscience $\quad 0270-6474 / 07 / 2711641-10 \$ 15.00 / 0$
}

2002; Chung et al., 2003; Vriens et al., 2004; Liedtke, 2005). In contrast, the most distant members, TRPV5 and TRPV6, do not respond to physical or chemical stimuli but are modulated by intracellular $\mathrm{Ca}^{2+}$ levels in the epithelium of the kidney and intestine (Nijenhuis et al., 2005; Nilius et al., 2007).

Structurally, a functional TRPV channel is a tetrameric membrane protein with four identical subunits assembled around a central aqueous pore (Kedei et al., 2001; Hoenderop et al., 2003). TRPV subunits preferentially, but not exclusively, assemble as homo-oligomers (Schaefer, 2005). Each subunit shows a topology of six transmembrane segments with a pore region between the fifth and sixth segment and cytoplasmic $\mathrm{N}$ and $\mathrm{C}$ termini (Montell, 2005; Ramsey et al., 2006). At the $\mathrm{N}$ terminus, TRPV monomers contain ankyrin domains that contribute to channel function (Jung et al., 2002) and subunit multimerization (Chang et al., 2004; Erler et al., 2004; Hellwig et al., 2005; Arniges et al., 2006) and are involved in protein-protein interactions with intracellular proteins that modulate their trafficking and function (Morenilla-Palao et al., 2004). A key role of the $\mathrm{N}$ terminus as a target for regulatory factors has been substantiated by its crystal packaging interactions (Jin et al., 2006; McCleverty et al., 2006). The protein also exhibits a cytosolic $\mathrm{C}$ terminus that harbors phosphoinositide, calmodulin binding domains, PKC consensus sites, and a TRP domain (Ramsey et al., 2006). In TRPV1, the TRP domain has been proposed to serve as a molecular determinant of subunit tetramerization (Garcia-Sanz et al., 2004). Noteworthy, this region appears involved in the functional modulation of TRP melastatin receptor (TRPM) channels by phosphoinositides (Rohacs et al., 2005; Rohacs and Nilius, 2007). Thus, in addition to its participation in TRPV subunit multim- 
erization, the TRP domain may also contribute to important aspects of channel function.

To address this question, we have replaced the TRP domain of TRPV1 with that of TRPV channels and evaluated the phenotype of the resulting chimeric channels. We uncover a dual functionality of the TRP domain of TRPV1 as a tetramerization domain and as a molecular determinant of channel gating. Examination of macroscopic ion channel activity of functional chimeras indicated that the TRP domain contributed to define the activation energy of channel opening.

\section{Materials and Methods}

TRPV1 chimeric design. TRPV1 chimeric channels containing the TRP domains [referred to as association domain (AD)] of TRPV2-TRPV6 were obtained by inserting the corresponding amino acid segments into the TRPV1 ( $\Delta 684-721)$ deletion mutant (Garcia-Sanz et al., 2004) using a Kpn21 restriction site. TRP domains were amplified by PCR from the corresponding TRPV channels using the following primers: AD2 (amino acids, 645-683 from human TRPV2; GenBank accession number

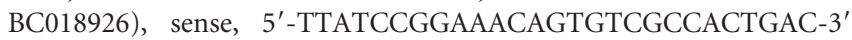
and antisense, 5'-TCTCTCCGGACCGCTGCTTCTTCCT-3'; AD3 (amino acids 677-716 from murine TRPV3; GenBank accession number Q8K424), sense, 5' -CTTATCCGGAGAGAACGTCTCCAAAGAAAG-3' and antisense, 5'-GCTCTCCGGAGCGGAATCTGCTTCTCAGCC-3'; AD4 (amino acids 718-757 from human TRPV4; GenBank accession number Q9HBA0), sense, 5'-GTACTCCGGAGGCCAGGTCTCCAAGGAG-3' and antisense, 5' -TCTCTCCGGAGCGGAAGGCCTTCCTCAG-3'; AD6 (amino acids, 578-616 from murine TRPV6; GenBank accession number Q91WD2), sense, 5'-GTGACTCCGGATGGAGAGTTGCCCATGAGCGAG-3' and antisense, 5'-CATATTCCGGAGCGAGGCCACAGGCAACGAGG-3'. The TRPV5-AD5 was generated from the TRPV1-AD6 by site-directed mutagenesis of residue H587 to Q. The sequence TCCGGA is the Kpn21 restriction site. Chimeric receptors were confirmed by DNA sequencing.

Cell culture and transfection. Human embryonic kidney HEK293 cells were cultured in DMEM supplemented with $10 \%$ fetal calf serum, $2 \mathrm{~mm}$ $\mathrm{L}$-glutamine, and $1 \%$ penicillin-streptomycin solution at $37^{\circ} \mathrm{C}$ in $5 \%$ $\mathrm{CO}_{2}$. Cells were transfected with $2 \mu \mathrm{g}$ of DNA encoding the TRPV1 and chimeric channels with Lipofectamine 2000 (Invitrogen, Carlsbad, CA) following the recommendations of the manufacturer. Cells were used $48 \mathrm{~h}$ after transfection.

Intracellular $\mathrm{Ca}^{2+}$ imaging. Transfected cells $\left(10^{6}\right.$ cells $\left./ \mathrm{cm}^{2}\right)$ were incubated with $5 \mu \mathrm{M}$ Fluo-4 AM (Invitrogen) in the presence of $0.02 \%$ pluronic F-127 (Biotium, Hayward, CA) in isotonic standard solution (in mM: $140 \mathrm{NaCl}, 4 \mathrm{KCl}, 2 \mathrm{MgCl}_{2}, 2 \mathrm{CaCl}_{2}, 5$ glucose, and $10 \mathrm{HEPES}, \mathrm{pH}$ 7.4). For $\mathrm{Ca}^{2+}$ imaging, cells were continuously perfused $(1 \mathrm{ml} / \mathrm{min})$ with isotonic standard solution at $20-22^{\circ} \mathrm{C}$. TRPV1 activity was evoked with $10 \mathrm{~s}$ pulses of capsaicin (Cap) ( 1 and $100 \mu \mathrm{M})$ using a multibarreled, gravity-driven perfusion system. Capsaicin stock solutions (Fluka, Siant Quentin Fallavier, France) (10 and $100 \mathrm{~mm}$ ) were prepared in dimethylsulfoxide and diluted as indicated in bath medium. Fluorescence measurements were performed with a Zeiss (Oberkochen, Germany) Axiovert 200 inverted microscope fitted with an ORCA-ER CCD camera (Hamamatsu, Bridgewater, NJ) through a $20 \times$ water immersion objective. Fluo- 4 was excited at $500 \mathrm{~nm}$ using computer-controlled Lambda 10-2 filter wheel (Sutter Instruments, Novato, CA), and emitted fluorescence was filtered with a $535 \mathrm{~nm}$ long-pass filter. Images were acquired and processed with AquaCosmos package software (Hamamatsu).

Confocal microscopy. Transfected cells $\left(\sim 2.5 \times 10^{5} \mathrm{cells} / \mathrm{cm}^{2}\right)$ were washed with PBS and fixed with $5 \%$ paraphormaldehyde $/ 4 \%$ sucrose for $20 \mathrm{~min}$ at $4^{\circ} \mathrm{C}$. Fixing solution was extensively washed out, and the fixed, intact cells were incubated with $5 \mu \mathrm{g} / \mathrm{ml}$ wheat germ agglutinin conjugated to Alexa Fluor 488 (Invitrogen) for $20 \mathrm{~min}$ at $20-22^{\circ} \mathrm{C}$ under continuous agitation and protected from light. The excess of the lectin was washed out with PBS, and cells were permeabilized with $3 \%$ horse serum, $2 \% \mathrm{BSA}$, and $0.1 \% \mathrm{NP}-40$ in PBS for $20 \mathrm{~min}$ at $20-22^{\circ} \mathrm{C}$ under mild agitation. Thereafter, cells were incubated with anti-TRPV1 (1:1000, guinea pig; Chemicon, Temecula, CA) overnight at $4^{\circ} \mathrm{C}$. After extensive washing, cells were exposed to cyanine-conjugated AffinityPure donkey anti-guinea pig (1:200; Jackson ImmunoResearch, West Grove, PA) for $1 \mathrm{~h}$ at $\sim 22^{\circ} \mathrm{C}$ under continuous agitation and protected from light. Cells were embedded and mounted in Vectashield Mounting medium (Vector Laboratories, Burlingame, CA) and analyzed by confocal microscopy in a Zeiss LSM 5 PASCAL.

Electrophysiology measurements in Xenopus oocytes. Capped cRNA was synthesized using the mMESSAGE mMACHINE from Ambion (Austin, TX). cRNA ( $2-5 \mathrm{ng}$ ) was microinjected (50 nl volume) into defolliculated oocytes (stage V and VI) as described previously (Ferrer-Montiel and Montal, 1999). Oocytes were functionally assayed $48-72 \mathrm{~h}$ after cRNA injection. Whole-cell currents from oocytes were recorded with a two-microelectrode voltage-clamp amplifier (Garcia-Martinez et al., 2000; Garcia-Sanz et al., 2004). Oocytes were continuously perfused (2 $\mathrm{ml} / \mathrm{min}$ ) with $\mathrm{Mg}^{2+}$-Ringer's solution (in mM: 10 HEPES $\mathrm{pH} 7.4,115$ $\mathrm{NaCl}, 2.8 \mathrm{KCl}, 0.1 \mathrm{BaCl}_{2}$, and $2.0 \mathrm{MgCl}_{2}$ ) at $20^{\circ} \mathrm{C}$. TRPV1 currents were activated with acidic solution $\left(\mathrm{Mg}^{2+}\right.$-Ringer's solution with $10 \mathrm{~mm}$ MES, pH 6.0) or $10 \mu \mathrm{M}$ capsaicin. The holding potential was kept at -60 $\mathrm{mV}$. Data acquisition and processing was performed in a NPI Electronic (Tamm, Germany) TEC10 two-microelectrode voltage-clamp amplifier with the Pulse/PulseFit version 8.5 software package (HEKA Elektronik, Lambrecht/Pfalz, Germany).

Patch-clamp measurements in HEK293 cells. HEK293 cells were cotransfected with TRPV1 species and the enhanced yellow fluorescent protein (Clontech, Mountain View, CA). Membrane currents were recorded with the whole-cell configuration using patch clamp. Patch pipettes were prepared from thin-walled borosilicate glass capillaries (World Precision Instruments, Sarasota, FL), pulled with a P-97 horizontal puller (Sutter Instruments) to have a tip resistance of 2-4 M $\Omega$ when filled with internal solution. For whole-cell recordings, pipette solution contained the following (in mM): $150 \mathrm{NaCl}, 3 \mathrm{MgCl}_{2}, 5$ EGTA, and 10 HEPES, pH 7.2 with $\mathrm{CsOH}$. The bath solution contained the following (in mM): $150 \mathrm{NaCl}, 6 \mathrm{CsCl}, 1 \mathrm{MgCl}_{2}, 1.5 \mathrm{CaCl}_{2}, 10$ glucose, and 10 HEPES, pH 7.4 with $\mathrm{NaOH}$. The different saline solutions were applied with a gravity-driven local microperfusion system with a rate flow of $\sim 200 \mu \mathrm{l} / \mathrm{min}$ positioned at $\sim 100 \mu \mathrm{m}$ of the recorded cells. All measurements were performed at $20-22^{\circ} \mathrm{C}$.

A voltage step protocol consisting of $50 \mathrm{~ms}$ depolarizing pulses from -120 to $300 \mathrm{mV}$ in steps of $20 \mathrm{mV}$ was used. The holding potential was 0 $\mathrm{mV}$, and the time interval between each pulse of the protocol was $5 \mathrm{~s}$. Current-voltage $(I-V)$ relationships were studied using a ramp protocol consisting of a voltage step of $300 \mathrm{~ms}$ from the holding potential of 0 to $-120 \mathrm{mV}$, followed by $350 \mathrm{~ms}$ linear ramp up to $160 \mathrm{mV}$. Time interval between each pulse was $10 \mathrm{~s}$. Data were sampled at $10 \mathrm{kHz}$ (EPC10 with pulse software; HEKA Elektronik) and low-pass filtered at $3 \mathrm{kHz}$ for analysis (PulseFit version 8.54; HEKA Elektronik). The series resistance was usually $<10 \mathrm{M} \Omega$ and, to minimize voltage errors, was compensated to $70-90 \%$.

The conductance-voltage ( $G-V$ ) curves were obtained by converting the maximal current values from the a $100 \mathrm{~ms}$ voltage step protocol (from -120 to $+160 \mathrm{mV})$ to conductance using the relation $G=I /\left(V-V_{\mathrm{R}}\right)$, where $G$ is the conductance, $I$ is the peak current, $V$ is the command pulse potential, and $V_{\mathrm{R}}$ is the reversal potential of the ionic current obtained form the $I-V$ curves. Conductance values from different cells were normalized to that of $+160 \mathrm{mV}$ and fitted to the Boltzmann equation: $G=$ $G_{\max } /\left\{1+\exp \left[\left(V-V_{0.5}\right) / a_{n}\right]\right\}$, where $G$ is the peak conductance, $G_{\max }$ is the maximal conductance, $V_{0.5}$ is the voltage required to activate the half-maximal conductance, and $a_{n}$ is the slope of the $G-V$ curve. The free energy difference for a two-state model at $0 \mathrm{mV}$ and $T=25^{\circ} \mathrm{C}\left(\Delta G_{0}\right)$ was calculated from $\Delta G_{0}=z_{g} \mathrm{~F} V_{0.5}$ (Caprini et al., 2005), where $\mathrm{F}$ is the Faraday constant $\left(0.023 \mathrm{kcal} \cdot \mathrm{mol}^{-1} \cdot \mathrm{mV}^{-1}\right)$, and $z_{g}$ is the apparent gating valence obtained using $z_{g}=25.69 \mathrm{mV} / a_{n}$. Data were analyzed with PulseFit version 8.11 (HEKA Elektronik) and Origin 7.0 (Microcal Software, Northampton, MA). Data were expressed as mean $\pm \mathrm{SD}$, with $n=$ number of cells. Statistical analysis was performed with Student's $t$ test, and a $p<0.05$ was taken as the level of significance.

Temperature stimulation. Coverslips with transfected HEK293 cells were placed in a microchamber and continuously perfused $(\sim 1 \mathrm{ml} / \mathrm{min})$ with solutions warmed at $25^{\circ} \mathrm{C}$. The temperature of the solutions was 


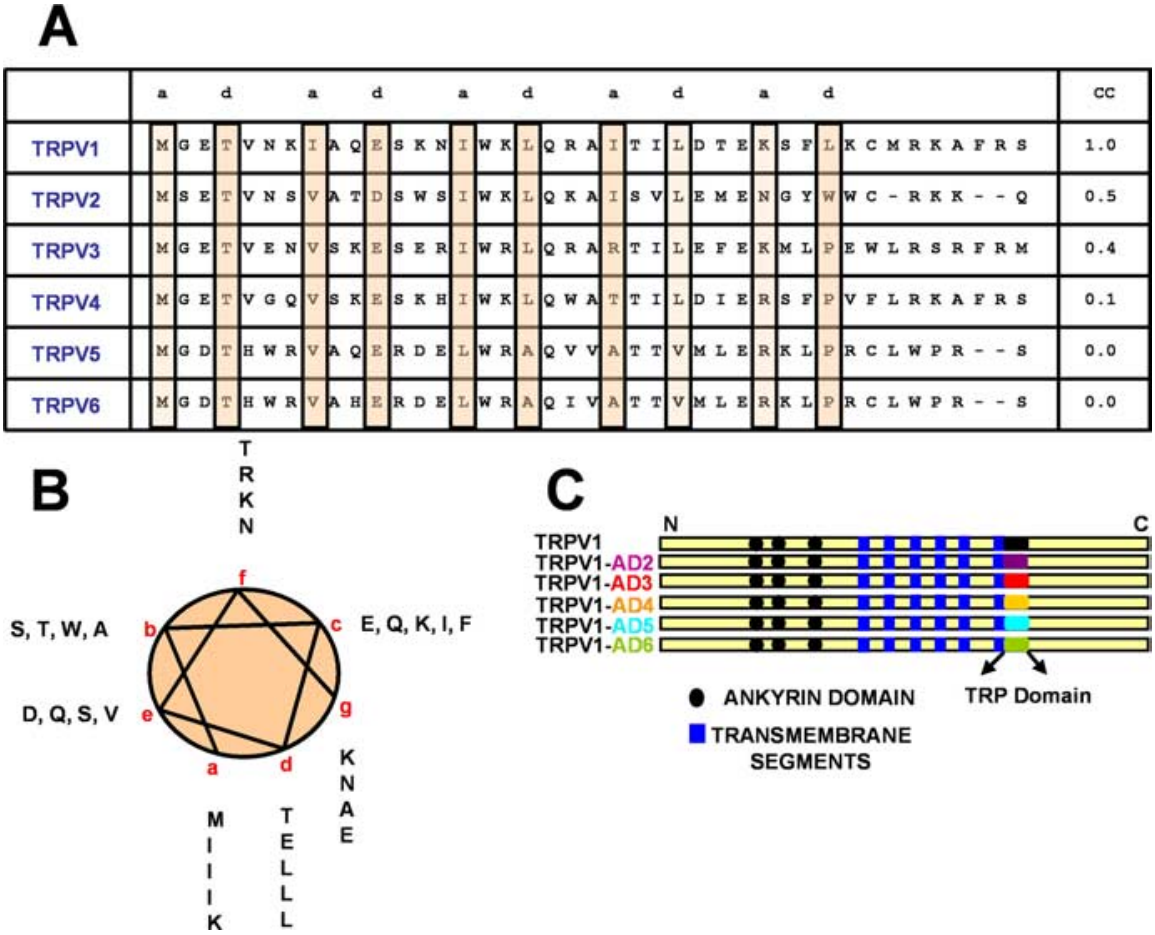

Figure 1. The TRP domain is conserved among TRPV channels. $\boldsymbol{A}$, Amino acid sequence alignment of the TRP domain of TRPV channels. The " $a$ " and " $d$ " positions of the predicted coiled coil are boxed. $\boldsymbol{B}$, Wheel representation of the TRP domain of TRPV1; in red are denoted the positions of a coiled coil. C, Diagram representing the design of TRPV1 chimeras in which the TRP domain (denoted as the AD) was replaced with the cognate of TRPV2 (TRPV1-AD2), TRPV3 (TRPV1-AD3), TRPV4 (TRPV1-AD4), TRPV5 (TRPV1-AD5), and TRPV6 (TRPV1-AD6). CC, Coiled coil score obtained in ExPASy Proteomic server (http://expasy.org/).

the predicted coiled coil correspond primarily to hydrophobic amino acids, whereas the rest of the positions were rich in polar and charged residues (Fig. $1 A, B$ ). Hydrophobic amino acids at the "a" and " $d$ " sites were large $(I, L)$ for most TRPV channels, except for distant family members TRPV5 and TRPV6 that displayed smaller residues $(\mathrm{V}, \mathrm{A})$, which reduced the coiled-coil score for these channels. Notably, coiled-coil structures have been shown to function as molecular determinants of subunit tetramerization in TRPV1 and TRPM8 channels (GarciaSanz et al., 2004; Tsuruda et al., 2006).

Previous studies shown that deletion of the TRP domain in TRPV $1(\Delta 684-721$ deletion mutant) decreased subunit oligomerization and fully abrogated channel functionality, implying that this region is essential for channel activity (Garcia-Sanz et al., 2004). Therefore, to gain additional insights on the functional role of the TRP domain in TRPV1, we investigated whether it could be replaced with the corresponding stretch of other TRPV channels. For this task, we inserted the TRP domain of TRPV2-TRPV6 into the TRPV1 ( $\Delta 684-721)$ mutant, thus creating a family of TRPV1 chimeras that only differed in their TRP domain (Fig. 1C). Chimeric proteins were heterologously expressed in

controlled using a CL-100 bipolar temperature controller and an SC-20 dual in-line heater/cooler and was measured by a TA-29 thermistor (Warner Instruments, Hamden, CT). The temperature probe was placed near the solution outflow and $<500 \mu \mathrm{m}$ of the patch-clamped cell. The time course of the temperature change was $\sim 0.3^{\circ} \mathrm{C} / \mathrm{s}$. Temperature ramps were first obtained at $-60 \mathrm{mV}$ and, thereafter, at $+50 \mathrm{mV}$ in the same cell.

Macroscopic ion currents were recorded with a Multiclamp amplifier using pClamp software and a Digidata 1322A digitizer (Molecular Devices, Palo Alto, CA). Voltage ramps consisted of a voltage step of $300 \mathrm{~ms}$ from the holding potential of 0 to $-120 \mathrm{mV}$, followed by $350 \mathrm{~ms}$ linear ramp up to $160 \mathrm{mV}$. Voltage-activated ramps were sampled at $2.5 \mathrm{kHz}$, and temperature ramps at -60 and $+50 \mathrm{mV}$ were sampled at $5 \mathrm{kHz}$ and low-pass filtered at $650 \mathrm{~Hz}$. Analysis was performed with pClamp9, WinASCD software [G. Droogmans, Katholieke Universiteit Leuven, Leuven, Belgium (ftp://ftp.cc.kuleuven.ac.be/pub/droogmans/winascd. zip)], and Origin 7.0 (Microcal). The activating threshold temperature $(T)$ and heat sensitivity $\left(Q_{10}\right)$ of channel gating was determined at +50 $\mathrm{mV}$. The threshold temperature was estimated as that which activates $10 \%$ of the maximal response. The $Q_{10}$ factor was obtained from the inverse slope of the $\log (I)$ versus $1 / T\left({ }^{\circ} \mathrm{K}\right)$ between $36^{\circ}$ and $46^{\circ} \mathrm{C}$ (Xu et al., 2002). Data were expressed as mean $\pm \mathrm{SD}$, with $n$ indicating number of cells. Statistical analysis was performed using the Student's $t$ test, and the $p<0.05$ was taken as the level of significance.

\section{Results}

Substitution of the TRP domain in TRPV1 by the corresponding of TRPV proteins did not affect receptor surface expression

An important molecular property of the TRP domain of TRPV1 was its propensity to fold as an $\alpha$-helix and to form coiled-coil structures (Garcia-Sanz et al., 2004; Lupas and Gruber, 2005). A representation of the heptad repeat sequence on a coiled-coil helical wheel revealed that amino acids at positions " $a$ " and " $d$ " of
Xenopus oocytes and HEK293 cells for functional characterization. We first investigated whether chimeras were assembled and delivered to the plasma membrane. Confocal microscopy, using specific fluorescent probes, showed that chimeras were expressed at the cell surface to an extent similar to TRPV1, as indicated by the colocalization of the channel immunoreactivity to a specific anti-TRPV1 antibody with the fluorescently labeled wheat agglutinin, a selective marker of glycosylated surface-expressed proteins (Fig. 2 A). The specificity of the lectin was verified by the lack of colocalization with the protein calnexin, a marker of endoplasmic reticulum (Fig. $2 \mathrm{~B}$ ). Accordingly, this result indicates that the TRP domain of TRPVs promoted the oligomerization and efficient membrane delivery of the TRPV1, suggesting a conserved role of this segment in subunit oligomerization in the TRPV family.

\section{Substitution of the TRP domain in TRPV1 by the cognate of TRPV proteins altered channel function}

We next questioned whether the chimeras were assembled as functional channels. For this purpose, we evaluated whether capsaicin could evoke $\mathrm{Ca}^{2+}$ influx into HEK293 cells expressing the different channel species. $\mathrm{Ca}^{2+}$-imaging experiments using Fluo- 4 as a fluorescent dye illustrated that 1 and $100 \mu \mathrm{M}$ capsaicin facilitated $\mathrm{Ca}^{2+}$ influx into cells expressing the TRPV1, TRPV1AD3, and TRPV1-AD4 proteins (Fig. 3). Similar results were obtained using the ratiometric $\mathrm{Ca}^{2+}$ dye fura-2 (supplemental Fig. S1, available at www.jneurosci.org as supplemental material). Quantitation of $\mathrm{Ca}^{2+}$ influx through TRPV1-AD3 and TRPV1-AD4 chimeras showed a significantly smaller, capsaicininduced intracellular $\mathrm{Ca}^{2+}$ rise than that seen through TRPV1 (supplemental Fig. S1, available at www.jneurosci.org as supple- 


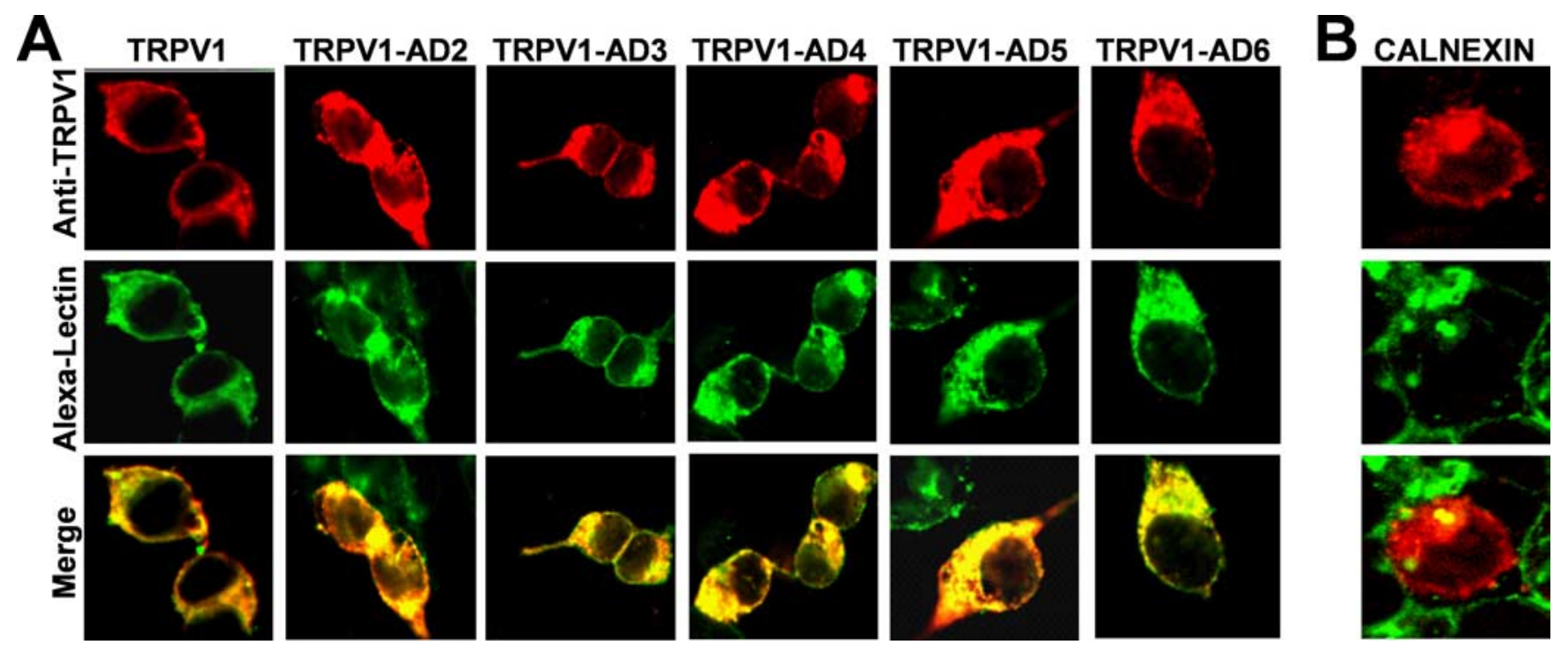

Figure 2. TRPV1 chimeras are expressed at the cell surface of HEK293 cells. A, Confocal microscopy images of HEK293 cells transfected with TRPV1 and chimeric subunits sequentially exposed to a fluorescently labeled wheat agglutinin (Alexa-Lectin) and to a specific anti-TRPV1 antibody against its N terminus. $\boldsymbol{B}$, Confocal images of untransfected HEK293 cells sequentially exposed to the fluorescent-lectin and anti-calnexin antibody, a selective marker of the endoplasmic reticulum. Fixed, intact cells were incubated with the fluorescent lectin and thereafter were permeabilized with detergent and incubated with the anti-TRPV1 or the anti-calnexin antibodies.

mental material), suggesting a lower vanilloid sensitivity of the chimeras. The increase in cytosolic $\mathrm{Ca}^{2+}$ mediated by both chimeras was attributable to activation of surface-expressed receptors, because this $\mathrm{Ca}^{2+}$ influx was abolished when the divalent cation was removed from the extracellular milieu (supplemental Fig. S1, available at www.jneurosci.org as supplemental material). In marked contrast, chimeras TRPV1-AD2, TRPV1-AD5, and TRPV1AD6 did not respond to either concentration of the agonist (Fig. 3) (supplemental Fig. S1, available at www.jneurosci.org as supplemental material), thus implying that these chimeric proteins did not produce functional channels or that the incorporation of these TRP domains into TRPV1 drastically impaired functional coupling.

To substantiate this finding, we evaluated the function of the chimeras with electrophysiological recordings from $\mathrm{Xe}$ nopus oocytes injected with cRNA encoding the different channel proteins. Because TRPV1 is a multimodal channel responding to vanilloids and extracellular acidic $\mathrm{pH}$, we used these two activating stimuli. As seen in Figure $4 A$, chimera TRPV1$\mathrm{AD} 3$ responded to both $\mathrm{pH} 6.0$ and $10 \mu \mathrm{M}$ capsaicin. Noteworthy, whereas the $\mathrm{pH}$ evoked currents exhibited a mean amplitude similar to wild type, the capsaicinactivated responses were approximately fourfold smaller (Fig. $4 B$ ), which resulted in a significantly lower $I_{\mathrm{Cap}} / I_{\mathrm{pH}}$ ratio (Fig. 4C). TRPV1-AD2 and TRPV1-AD4 chi-
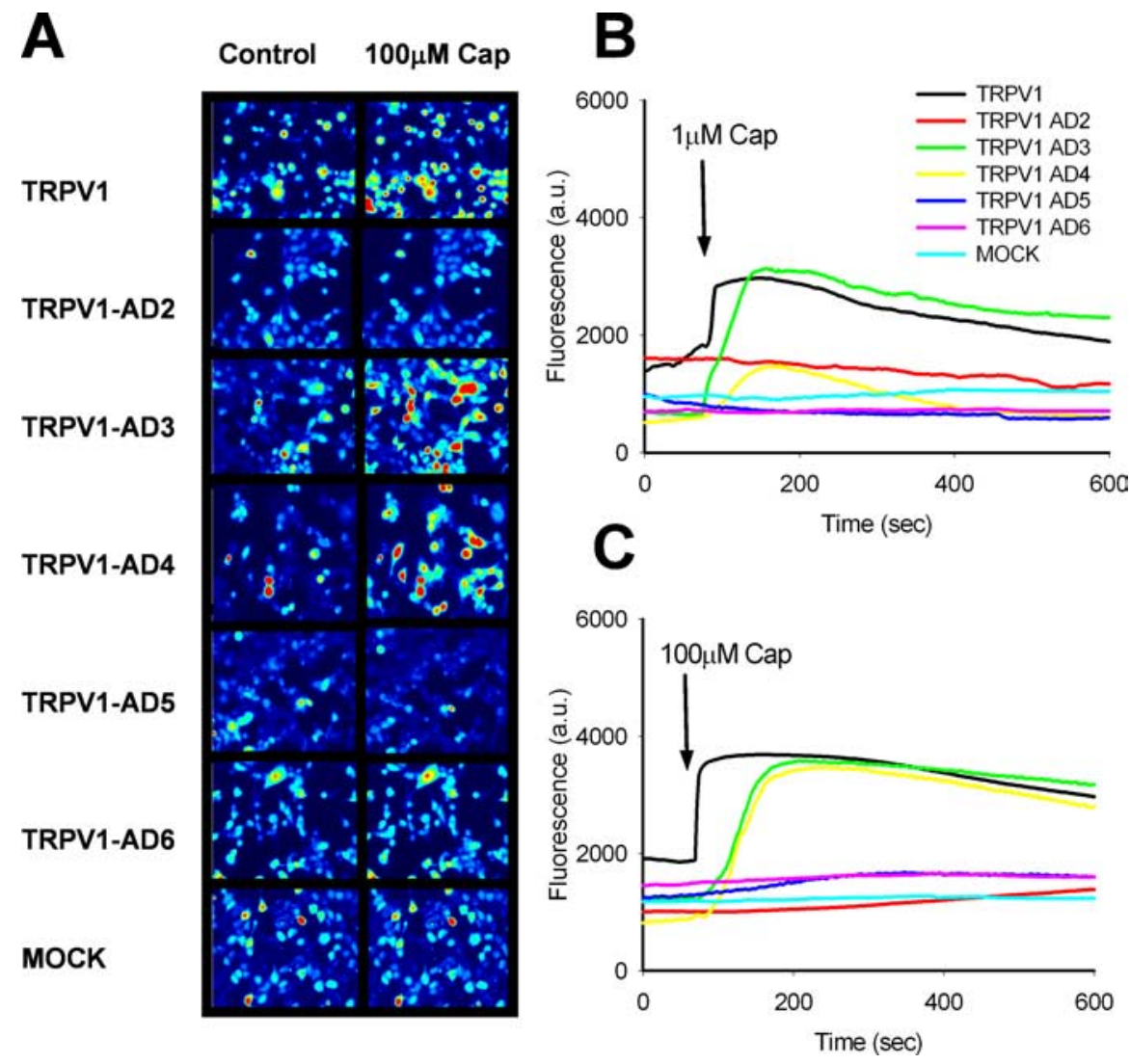

Figure 3. TRPV1-AD3 and TRPV1-AD4 chimeras display capsaicin-evoked $\mathrm{Ca}^{+2}$ influx. $\boldsymbol{A}, \mathrm{Ca}^{2+}$ images showing the intracellular rise in $\mathrm{Ca}^{+}$evoked by $100 \mu \mathrm{m}$ capsaicin from HEK293 cells expressing the different TRPV1 species or mock-transfected cells. $\boldsymbol{B}, \boldsymbol{C}$, Change in $\mathrm{Ca}^{2+}$-dependent fluorescence of TRPV1-transfected and mock cells as a function of time, before and after the exposure to 1 and $100 \mu \mathrm{m}$ for $10 \mathrm{~s}$ at $20-22^{\circ} \mathrm{C}$, respectively. Representative images and traces of 50 cells measured in $n=3$ different experiments. Traces represent that change in fluorescence per cell. Cells were loaded with Fluo-4 AM to record intracellular calcium signals and activated as indicated. The extracellular concentration of $\mathrm{Ca}^{2+}$ was $2 \mathrm{~mm}$. The arrows indicate the onset of capsaicin exposure. 
A

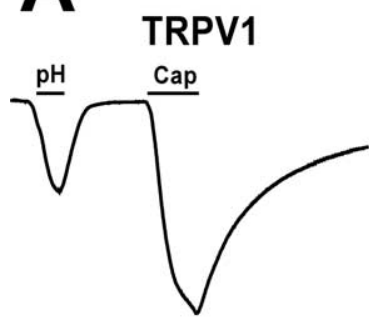

TRPV1-AD4

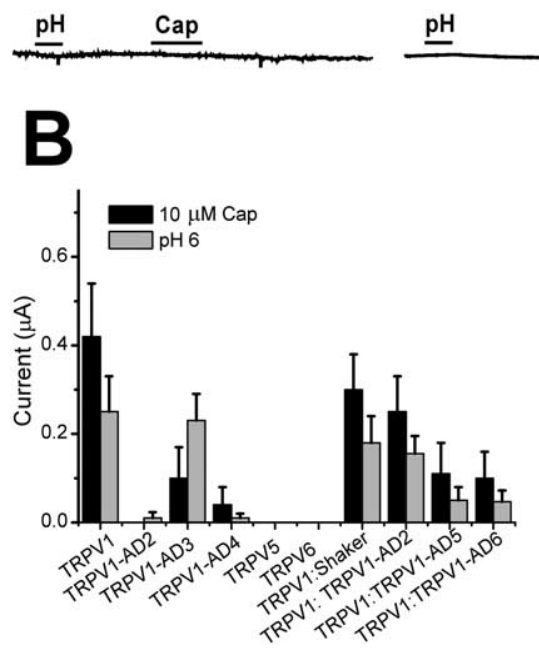

TRPV1-AD5

Cap

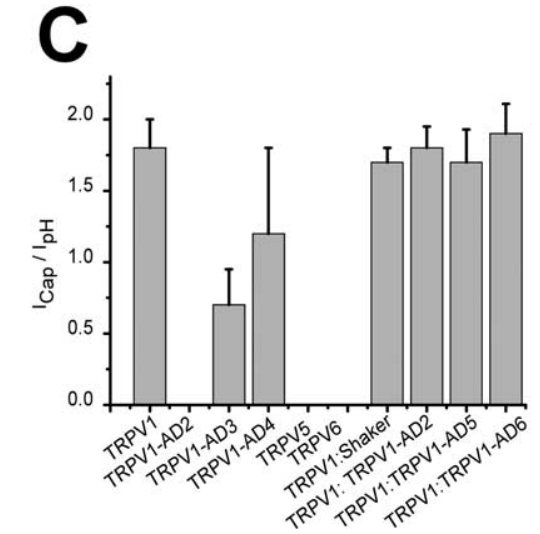

Figure 4. Expression of chimeric channels in Xenopus 0ocytes. $A$, lonic currents activated by pH 6.0 and $10 \mu \mathrm{m}$ capsaicin from amphibian oocytes injected with the cRNA encoding TRPV1 and chimeric channels. Oocytes were held at $-60 \mathrm{mV}$. Ionic currents were measured $48-72 \mathrm{~h}$ after cRNA injection in $\mathrm{Mg}^{2+}$-Ringer's solution at $20^{\circ} \mathrm{C}$. Current traces are representative of $n \geq 3$ 0ocytes. $\boldsymbol{B}$, Mean amplitude of ionic currents elicited by pH 6.0 and $10 \mu \mathrm{m}$ capsaicin. $C, I_{\mathrm{Cap}} / I_{\mathrm{pH}}$ ratio for TRPV1 and chimeric channels calculated form the recordings shown in $A$. Data are shown as mean $\pm S D$, with number of oocytes of $n \geq 3$.

meras displayed barely detectable ionic currents at $\mathrm{pH} 6.0$ but were unresponsive to $10 \mu \mathrm{M}$ capsaicin (Fig. $4 A-C$ ), whereas TRPV1-AD5 and TRPV1-AD6 chimeras did not show visible channel function (Fig. 4A-C). Because all these chimeras expressed at the cell surface, we evaluated whether they coassembled with wild-type subunits using a coexpression approach. Coinjection of TRPV1-AD2 with wild-type subunits at a ratio of $1: 1(\mathrm{w} / \mathrm{w})$ produced capsaicin and $\mathrm{pH}$ responses that were $25 \%$ lower than those characteristic of TRPV1 channels (Fig. $4 B$ ) (supplemental Fig. S2, available at www.jneurosci.org as supplemental material) and exhibited a similar $I_{\mathrm{Cap}} / I_{\mathrm{pH}}$ ratio to wildtype channels. The lack of a dominant-negative phenotype for TRPV1-AD2 is consistent with the presence of functional homomeric TRPV1 channels and some heteromeric assemblies of TRPV1 and TRPV1-AD2 monomers. A similar result was obtained for coinjection of TRPV4 with TRPV1 (data not shown).

In marked contrast, coinjection of TRPV1-AD5 and TRPV1AD6 chimeras with TRPV1 monomers gave rise to $\mathrm{pH}$ and vanilloid responses that were $75 \%$ smaller than those recorded from homomeric TRPV1 receptors (Fig. 4B) (supplemental Fig. S2, available at www.jneurosci.org as supplemental material), which is consistent with a dominant-negative phenotype of these two chimeras on TRPV1 subunits. This dominant-negative phenotype was not attributable to a translational inhibition of TRPV1 monomers because coinjection of TRPV1 with the voltage-gated $\mathrm{K}^{+}$Shaker channel, a protein that does not coassemble with TRPV1 subunits and is highly expressed in oocytes, did not affect significantly the capsaicin and $\mathrm{pH}$-evoked currents (Fig. 4B) (supplemental Fig. S2, available at www.jneurosci.org as supplemental material). Similarly, coinjection of TRPV1-AD5 and TRPV1-AD6 chimeras with Shaker subunits did not alter the functional expression of neither Shaker channels nor their voltage sensitivity (data not shown). Therefore, TRPV1-AD5 and TRPV1-AD6 chimeras appear to assemble nonfunctional heteromeric receptors with TRPV1. Collectively, these results suggest that TRPV1-AD3 and TRPV1-AD4 chimeras form activatable channels, whereas TRPV1-AD2, TRPV1-AD5, and TRPV1AD6 assemble receptors that do not respond to the activating stimuli. Therefore, in addition to its role in subunit oligomerization, the TRP domain seems important for TRPV1 channel activity.

Functional chimeric channels displayed an altered voltage-dependent gating We next studied the voltage-dependent channel activity of the chimeras in the absence and presence of capsaicin by patch clamp. TRPV1 and chimeras were heterologously expressed in HEK293 cells, and their voltage-activated responses were studied with whole cell using a voltage step and ramp protocol at $\sim 22^{\circ} \mathrm{C}$ (Voets et al., 2004). Stimulation with $50 \mathrm{~ms}$ depolarizing voltage steps from -120 to $+300 \mathrm{mV}$ elicited non-inactivating macroscopic currents from TRPV1 wild-type channels but not in mock-transfected cells (Fig. 5). A $G-V$ curve yielded a $V_{0.5}$ for TRPV1 of $119 \pm 2 \mathrm{mV}(n=8)$ and a gating valence $\left(z_{g}\right)$ of $0.75 \pm 0.07$, similar to values reported previously (Voets et al., 2004). Remarkably, none of the chimeras expressed voltage-dependent channel activity when depolarized with this family of potential steps (Fig. 5), suggesting that either the voltage sensor was disrupted or that voltage sensing was uncoupled from channel opening in chimeric channels.

Because capsaicin strongly modulates the voltage-dependent gating of TRPV 1 by displacing the $G-V$ relationship toward physiological voltages, i.e., to more negative potentials (Voets et al., 2004), we next evaluated the effect of capsaicin on the voltagedependent activation of these chimeras. For this purpose, we obtained $I-V$ relationships from -120 to $+160 \mathrm{mV}$ at increasing concentrations of the vanilloid. As illustrated in Figure 5, addition of $1 \mu \mathrm{M}$ capsaicin resulted in large outward rectifying currents for TRPV1 that reversed at $5 \pm 3 \mathrm{mV}(n=3)$. Higher concentrations of the vanilloid could not be used on TRPV1 because they evoke sizable currents at positive potentials that lead to large clamp errors. HEK293 cells expressing the TRPV1-AD3 chimera responded well to increasing concentrations of capsaicin giving rise to outward rectifying $I-V$ curves akin to wild-type channels (Fig. 5). These ionic currents reversed at $-3 \pm 5 \mathrm{mV}$, indicating that swapping of the TRP domain did not apparently affect the channel permeation properties. In marked contrast, the chimera TRPV1-AD4 exhibited modest ionic currents at high concentrations of capsaicin, and chimeras TRPV1-AD2, TRPV1-AD5, and TRPV1-AD6 did not show vanilloid-induced, 
voltage-dependent responses (Fig. 5). Note that the small ionic current seen in cells expressing the TRPV1-AD4 was mediated by the chimera because it was completely and reversibly blocked by the noncompetitive antagonist Arg-1515C (data not shown) (Garcia-Martinez et al., 2006).

To further characterize the functional properties of the TRPV1-AD3 chimera, we studied the biophysical properties of macroscopic channel gating. First, we investigated its capsaicin sensitivity. As illustrated in Figure $6 A$, the magnitude of the ionic currents increased as a function of the vanilloid concentration. Analysis of the current density reveals a maximal value of $0.18 \pm 0.06 \mathrm{nA} / \mathrm{pF}(n=5)$ at 160 $\mathrm{mV}$ in the presence of $100 \mu \mathrm{M}$ capsaicin (Fig. 6B), which is at least fivefold lower than that exhibited by TRPV1 channels in the presence of $1 \mu \mathrm{M}$ of the vanilloid. In addition, dose-response curves for capsaicin revealed that the chimera was $\sim 10$ fold less sensitive to the vanilloid than wild-type channels $\left(\mathrm{EC}_{50}\right.$ of $10 \pm 2 \mu \mathrm{M}$ for TRPV1-AD3 and $0.9 \pm 0.3 \mu \mathrm{M}$ for TRPV1) (Fig. 6C). The Hill coefficient of the curve was also reduced in the chimeric channel (Fig. 6C). Collectively, these observations indicate that this chimera has decreased vanilloid sensitivity that appears to arise from a change in the maximal response and the vanilloid efficacy of gating.

Second, we obtained the $G-V$ curves at increasing concentrations of capsaicin. For TRPV1, the vanilloid produced a leftward shift toward hyperpolarized potentials of the $G-V$ curve $\left(V_{0.5}=\right.$ $62 \pm 3 \mathrm{mV} ; n=3)$ without affecting its voltage dependency $\left(z_{g}=\right.$ $0.64 \pm 0.05 ; n=3$ ) (data not shown). Similarly, capsaicin induced a dose-dependent leftward shift of the activation curve of the chimera toward lower potentials (Fig. 7A). Fitting of the normalized curves to a Boltzmann distribution revealed a marked $\sim 68 \mathrm{mV}$ hyperpolarizing shift in $V_{0.5}$ when the vanilloid was increased from 1 to $100 \mu \mathrm{M}$ (Fig. $7 B$ ), without significantly altering the gating valence of channel opening $\left(z_{g}=0.8-1.0\right)$ (Fig. $7 C)$. These findings suggest that substitution of the TRP domain affected the activation energy of channel opening rather than its voltage-dependent gating. Indeed, inspection of the free energy difference between the closed and the open state at $0 \mathrm{mV}$ and $T=$ $25^{\circ} \mathrm{C}\left(\Delta G_{\mathrm{o}}\right)$ obtained from $V_{0.5}$ and $z_{g}$ of the $G-V$ relationship (Caprini et al., 2005), considering a simplistic, two-state model, showed that capsaicin produced a dose-dependent decrease of the activation energy of channel gating (Fig. 7D). A comparison of the $\Delta G_{\mathrm{o}}$ for TRPV1 and TRPV1-AD3, obtained in the presence of a capsaicin concentration that equals their respective $\mathrm{EC}_{50}$ (Fig. 6C), indicates that the chimera activated at higher potentials $(62 \pm 2 \mathrm{mV}, n=5$ for TRPV $1 ; 79 \pm 3 \mathrm{mV}, n=5$ for TRPV1AD3) and required $0.9 \mathrm{kcal} / \mathrm{mol}$ more energy for gating than wild-type channels $(0.92 \pm 0.12 \mathrm{kcal} / \mathrm{mol}$ for TRPV1 and $1.83 \pm$ $0.16 \mathrm{kcal} / \mathrm{mol}$ for TRPV1-AD3). Together, these results support a role of the TRP domain defining the energetics of channel gating and suggest that this domain may be important for coupling voltage sensing to channel opening.
TRPV1-AD3

TRPV1-AD2
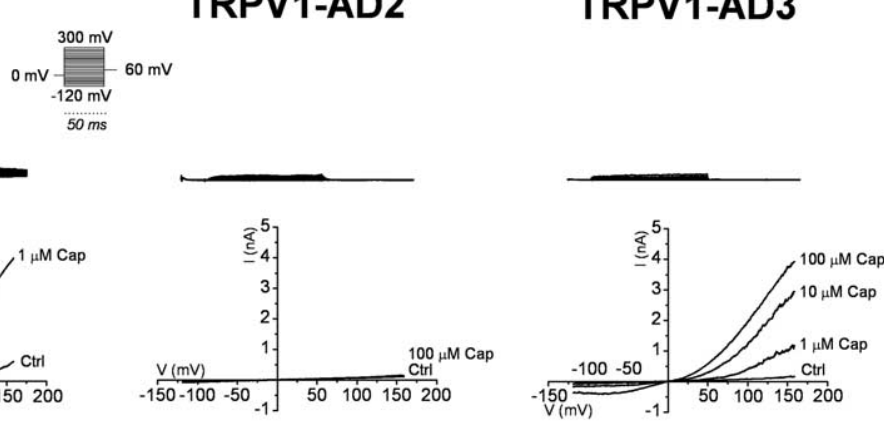

TRPV1-AD6

TRPV1-AD5

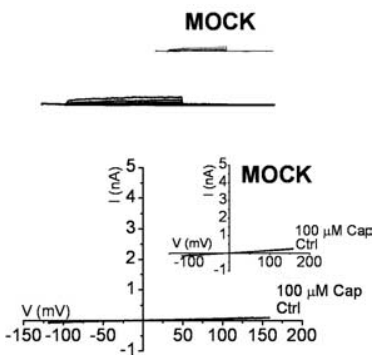

Figure 5. Voltage-dependent gating of TRPV1 and chimeras expressed in HEK293 cells. Representative family of whole-cell currents elicited with a voltage protocol consisting of $50 \mathrm{~ms}$ depolarizing pulses from -120 up to $300 \mathrm{mV}$ in steps of $20 \mathrm{mV}$. I $-\mathrm{V}$

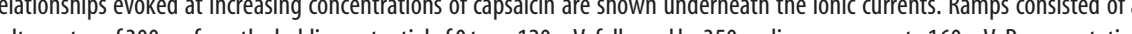
current traces from $n \geq 6$ cells are shown. Whole-cell currents were obtained in symmetrical $150 \mathrm{~mm} \mathrm{NaCl}$, from a holding potential of $0 \mathrm{mV}$. Ctrl, I-V curves obtained in the absence of capsaicin.

\section{Functional chimeric channels exhibited reduced heat sensitivity}

Because the C terminus of TRPV1 is a key molecular determinant of heat sensing (Vlachova et al., 2003; Brauchi et al., 2006), we next investigated the heat sensitivity of our chimeric channels to determine the contribution of the TRP domain. For this purpose, we obtained temperature-evoked responses at -60 and $+50 \mathrm{mV}$, as well as $I-V$ curves at $25^{\circ} \mathrm{C}$ and $46^{\circ} \mathrm{C}$ (Fig. 8). Heat-activated ionic currents from TRPV1 channels at both membrane potentials were readily obtained (Fig. $8 \mathrm{~A}$ ). At variance with capsaicinevoked responses, these ionic currents displayed a strong outward rectification characterized by a virtual lack of ionic currents at negative potentials (Fig. $8 \mathrm{~B}$ ). TRPV1-AD3 chimera exhibited heat-activated currents that were on average 10 -fold smaller than those of wild type (Figs. $8 \mathrm{~A}, 9$ ) but characterized by an outward rectifying $I-V$ relationship such as that of TRPV1 (Fig. $8 B$ ). In contrast, the other four chimeras did not produce measurable heat-activated currents at $-60 \mathrm{mV}$, although a small, detectable response could be observed for TRPV1-AD2 and TRPV1-AD4 at highly depolarized potentials ( $\geq 100 \mathrm{mV}$ ) (Figs. 8 B, 9), compatible with their poor response to the other activating stimuli used. Accordingly, replacement of the TRP domain of TRPV1 with that of TRPV channels affected the temperature sensitivity of channel gating, implying a potential role of this protein region in temperature sensing.

We next determined the threshold temperature of channel activation from the $I-T$ relationships for TRPV1 and TRPV1AD3. This value was defined as the temperature that activated $10 \%$ of the maximal response and was obtained only at $+50 \mathrm{mV}$ for both TRPV1 species because the heat-evoked currents of the 

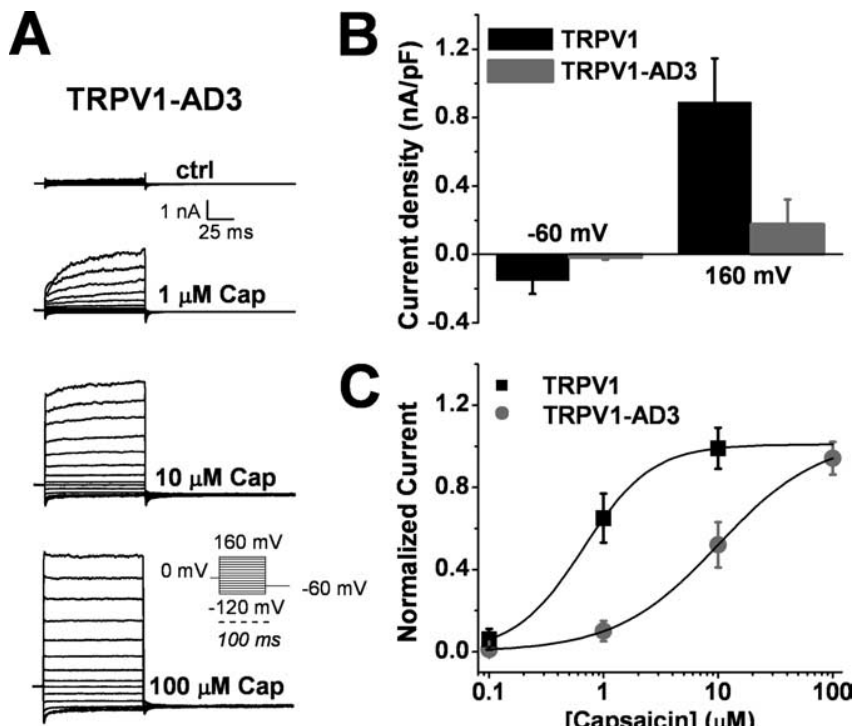

Figure 6. Capsaicin-evoked ionic currents from TRPV1-AD3 chimeras. A, Representative family of whole-cell currents elicited with a voltage protocol consisting of $100 \mathrm{~ms}$ depolarizing pulses from -120 up to $160 \mathrm{mV}$ in steps of $20 \mathrm{mV}$ for TRPV1-AD3 at increasing concentrations of capsaicin. $B$, Current densities of TRPV1 and TRPV1-AD3 evoked in the presence of capsaicin at -60 and $160 \mathrm{mV}$. Ionic currents from TRPV1-AD3 were activated by $100 \mu \mathrm{m}$ capsaicin, whereas those of TRPV1 were evoked by $1 \mu \mathrm{m}$. Higher capsaicin concentrations could not be used for TRPV1 because the large currents evoked at positive potentials could not be clamped. $C$, Dose-response relationships for capsaicin activation of TRPV1 and TRPV1-AD3 chimera. Channel activity was elicited at a holding potential of $-60 \mathrm{mV}$. Solid lines depict the theoretical fits to a Michaelis-Menten binding isotherm (Garcia-Martinez et al. 2006). The $\mathrm{EC}_{50}$ values for capsaicin were $0.9 \pm 0.2 \mu \mathrm{m}$ for TRPV1 and $10 \pm 2 \mu \mathrm{m}$ for TRPV1-AD3. The Hill coefficients were $1.8 \pm 0.2$ for TRPV1 and $1.4 \pm 0.2$ for TRPV1-AD3. Responses were normalized to the maximal capsaicin-evoked ionic current inferred from the fit of the dose-response curves depicting the total ionic current recorded at increasing concentrations of capsaicin. Each point represents the mean $\pm S D$, with $n=4$. ctrl, $I-V$ curves obtained in the absence of capsaicin.

chimera at $-60 \mathrm{mV}$ were too small to obtain a reliable value. TRPV1 activated at $36 \pm 2{ }^{\circ} \mathrm{C}(n=8)$ and TRPV1-AD3 at $33 \pm$ $3^{\circ} \mathrm{C}(n=3)$, thus demonstrating that replacement of the TRP domain did not alter the threshold temperature of channel gating. In contrast, both channels exhibited differences in the temperature dependence of the gating process determined as the $Q_{10}$ value (Liu et al., 2003; Brauchi et al., 2004). Whereas TRPV1 exhibited a mean $Q_{10}$ of $25 \pm 7(n=8)$, the chimera was characterized by an approximate twofold smaller value, i.e., $11 \pm 5(n=$ 3 ; $p<0.05$ ), which lends support to the tenet that lower heat responses of TRPV1-AD3 were primarily attributable to uncoupling of temperature sensing from channel opening rather than an alteration of the temperature sensor.

To further address this issue, we investigated the effect of raising the temperature to $45^{\circ} \mathrm{C}$ on the capsaicin responses from TRPV1-AD2, TRPV1-AD3, and TRPV1-AD4 (Fig. 10). For wild-type channels, heat did not augment significantly the ionic currents evoked by $1 \mu \mathrm{M}$ capsaicin (Fig. 10A). Similarly, heat did not potentiate the response to $1 \mu \mathrm{M}$ vanilloid of TRPV1-AD2 that was primarily insensitive to capsaicin. In marked contrast, the vanilloid responses of TRPV1-AD3 and TRPV1-AD4 chimeras were increased by at least fivefold when recorded at $45^{\circ} \mathrm{C}$ (Fig. $10 B, C)$. Note that both the vanilloid and heat responses were potentiated when the activating stimuli were applied simultaneously. Collectively, these observations further substantiate the notion that these chimeric channels have an altered functional coupling and imply that the TRP domain plays a role in channel gating.
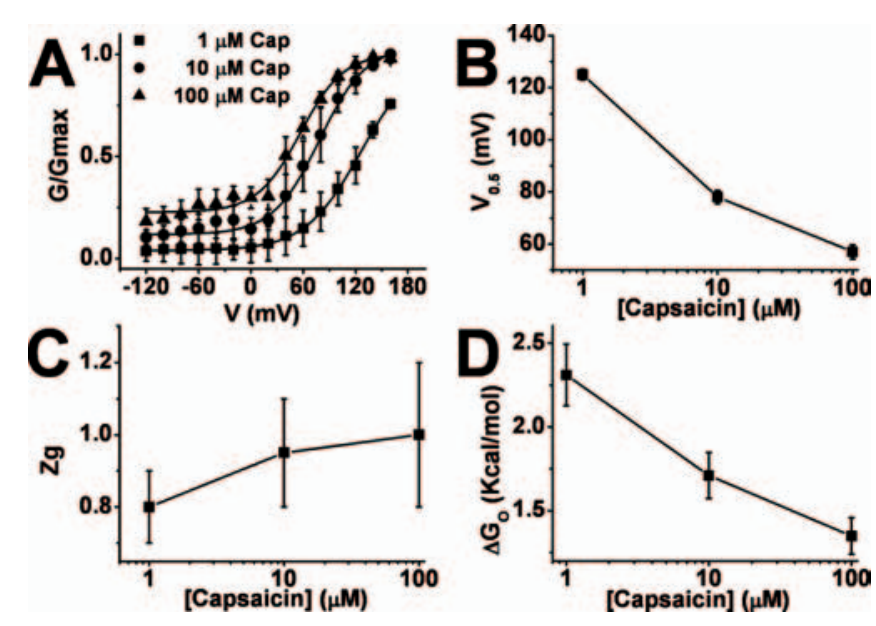

Figure 7. Voltage-dependent properties of TRPV1-AD3 chimera. A, G-V relationships of TRPV1-AD3 at increasing concentrations of capsaicin (1-100 $\mu \mathrm{M})$. The $G-V$ curves were obtained by converting the maximal current values from a voltage step protocol shown in Figure $6 \mathrm{~A}$ to conductance using the relation $G=I /\left(V-V_{R}\right)$, where $G$ is the conductance, $/$ is the peak current, $V$ is the command pulse potential, and $V_{R}$ is the reversal potential of the ionic current obtained form the $I-V$ curves. Solid lines depict the best fit to a Boltzmann distribution. $B, C$, Variation of the $V_{0.5}(\boldsymbol{B})$ and $z_{g}(\boldsymbol{C})$ of TRPV1-AD3 as a function of the capsaicin concentration, respectively. The apparent gating valence of the activation process obtained using $z_{g}=25.69$ $\mathrm{mV} / a_{n}$, where $a_{n}$ is the slope of the $G-V$ curves. $V_{0.5}$ and $a_{n}$ values were obtained from the fit of $G-V$ relationships depicted in $\boldsymbol{A}$ to a Boltzmann distribution. $\boldsymbol{D}$, Variation of the free energy $\left(\Delta G_{0}\right)$ as a function of the capsaicin concentration. The $\Delta G_{0}$ was obtained from $\Delta G_{0}=z_{g} F V_{0.5}$, where $\mathrm{F}$ is the faraday constant $\left(0.023 \mathrm{kcal} \cdot \mathrm{mol}^{-1} \cdot \mathrm{mV}^{-1}\right)$. Data are given as mean $\pm \mathrm{SD}$, with $n \geq 5$ cells. ${ }^{*} p<0.05$ obtained with the Student's $t$ test.

\section{Discussion}

The TRP domain of TRPV channels is a segment adjacent to the inner pore helix that acts as a molecular determinant of subunit multimerization (Chang et al., 2004; Garcia-Sanz et al., 2004). However, the equivalent region in TRPM channels has been shown to contribute to channel activation and desensitization by phosphoinositides (Rohacs and Nilius, 2007). Thus, we reasoned that the TRP domain may be also a molecular determinant of channel activity. Noteworthy, the salient contribution of our study is the identification that the TRP domain has a dual functionality, serving as a tetramerization domain that is also important for the correct coupling of the activating stimulus to channel opening.

The basic observation of our study was that the TRP domain of TRPV1 can be functionally swapped with the cognate TRPV2TRPV4, although substitution with that of TRPV2 produced chimeric channels with barely detectable heat- and $\mathrm{pH}$-activated channel activity but not capsaicin-gated responses. In contrast, incorporation of the corresponding domains of TRPV5 and TRPV6 did not produce functional channels, but they gave rise to TRPV1 channels that were properly assembled and trafficked to the plasma membrane. This finding implies that the subunit oligomerization function of the TRP domain appears conserved and exchangeable within the TRPV family and raises the possibility of subunit hetero-oligomerization between its members if their assembly were only determined by this protein domain. However, despite the overall structural similarity of the TRP domain, coassembly of TRPV subunits has been limited to complexes of thermo TRPVs and TRPV5-TRPV6 (Hoenderop et al., 2003; Hellwig et al., 2005; Schaefer, 2005), consistent with the tenet that the TRP domain is unlikely to be the only region responsible of subunit-subunit interactions. Indeed, our observation that the TRP domain could be replaced with that of TRPVs without losing 


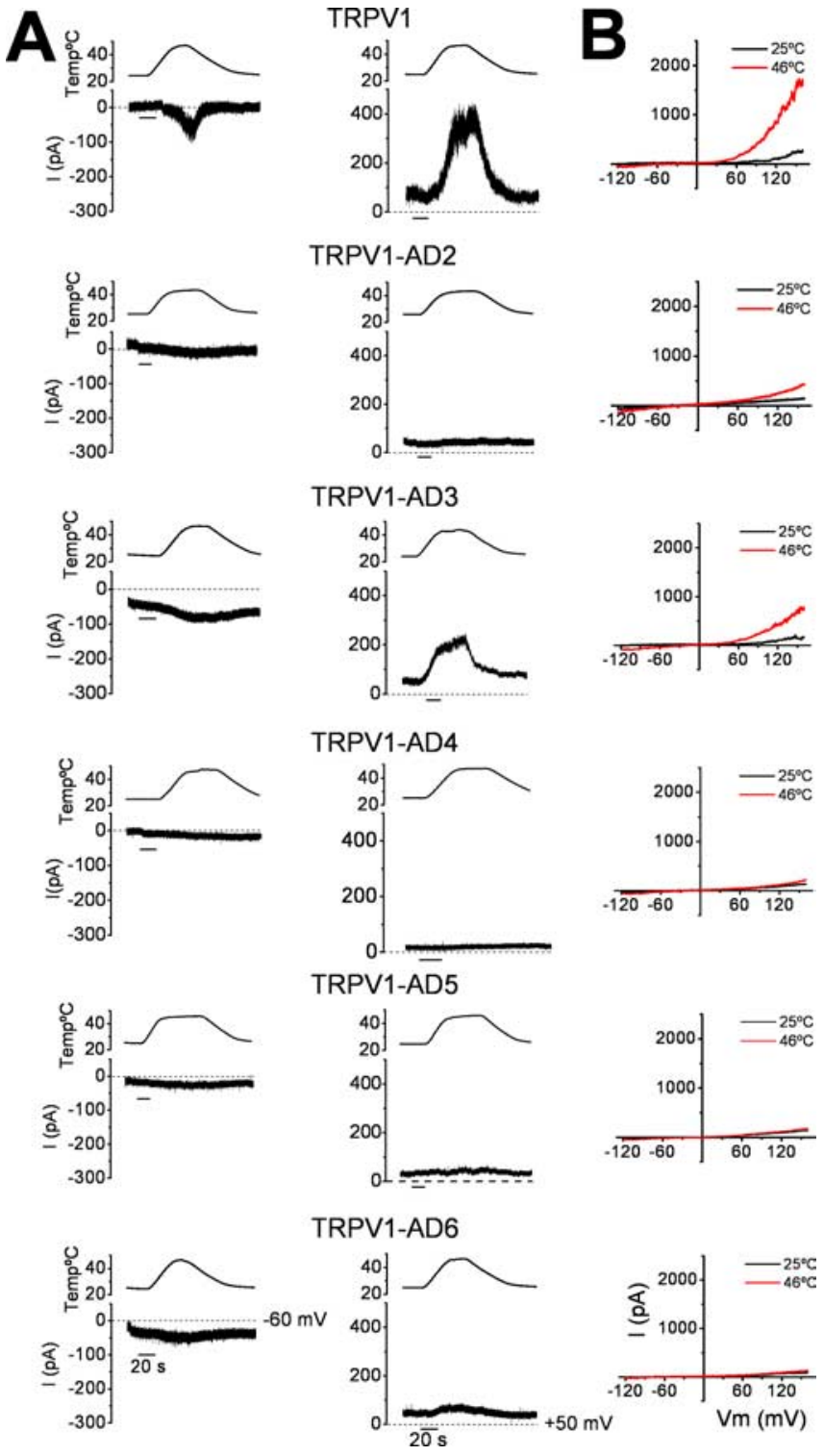

Figure 8. Heat-dependent gating of TRPV1 and chimeric channels. $\boldsymbol{A}$, Traces represent the ionic currents evoked by heat ramps (depicted on top, $0.3^{\circ} \mathrm{C} / \mathrm{s}$ ) from cells held at $-60 \mathrm{mV}$ (left) and $+50 \mathrm{mV}$ (right). $\boldsymbol{B}, I-V$ curves obtained at $25^{\circ} \mathrm{C}$ and $46^{\circ} \mathrm{C}$ for wild-type and chimeric channels. Cells were depolarized from -120 to $+160 \mathrm{mV}$ in $350 \mathrm{~ms}$ with a linear ramp. Traces are representative of $n \geq 3$ cells.

the ability to assemble as homomers, and heteromers with TRPV1, substantiates that other channel domains such as the $\mathrm{N}$ terminus and the membrane-spanning segments may participate in subunit tetramerization (Hellwig et al., 2005; Arniges et al., 2006).

We found that the lack of activity of a truncated TRPV1 mutant missing the TRP domain could be rescued by inserting the sequence TRPV3 and TRPV4 as exemplified by the chimeras TRPV1-AD3 and TRPV1-AD4 and to a lesser extent by TRPV1AD2. However, these chimeras were less sensitive to the activating stimuli than wild-type channels. Noteworthy, at variance with TRPV1, chimeric channels did not show voltage-activated currents in resting conditions, implying that the coupling between the voltage sensor and the channel gate was compromised. Nevertheless, voltage-dependent gating was not fully abolished because it was evident in the presence of capsaicin or heat. Biophysical analysis of macroscopic currents of the more active chi-

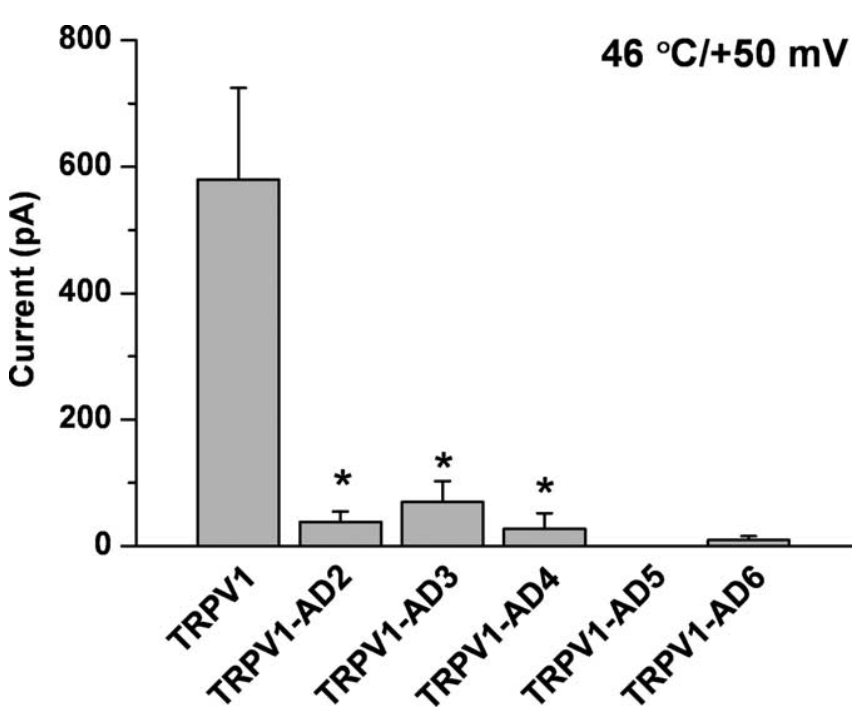

Figure 9. Temperature-dependent properties of wild-type and TRPV1-AD3 chimera. Mean amplitude of the ionic currents evoked by a heat ramp from $25^{\circ} \mathrm{C}$ to $46^{\circ} \mathrm{C}$ recorded at $+50 \mathrm{mV}$ and $46^{\circ} \mathrm{C}$ for TRPV1 and chimeric channels. Ionic currents were obtained from the recordings shown in Figure 7. Data are given as mean $\pm S D$, with $n \geq 3$ cells. ${ }^{*} p<0.05$ obtained with Student's $t$ test.
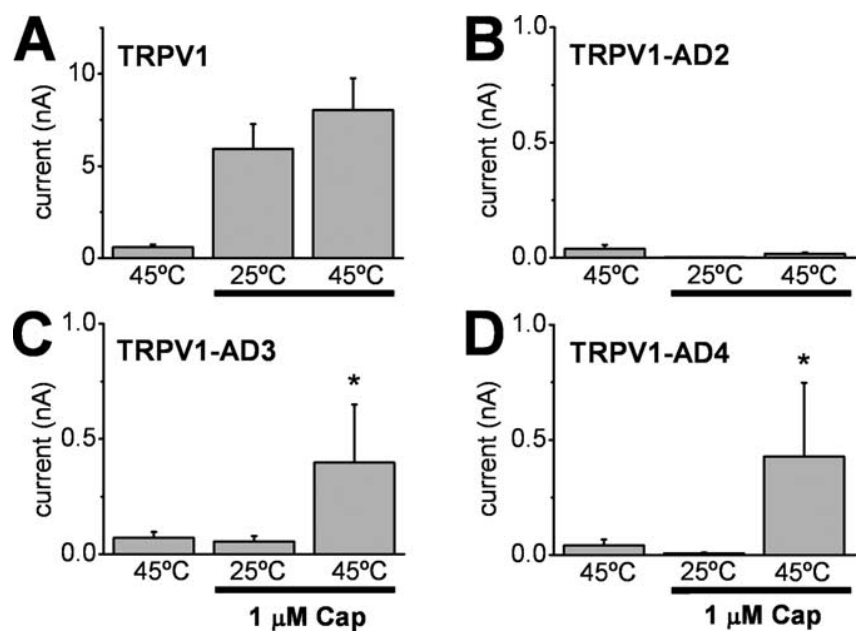

Figure 10. Effect of heat on the capsaicin responses of TRPV1, TRPV1-AD2, TRPV1-AD3, and TRPV1-AD4 chimeras. Mean amplitude of the ionic currents evoked by heat $\left(45^{\circ} \mathrm{C}\right)$ and 1 $\mu \mathrm{m}$ capsaicin at $25^{\circ} \mathrm{C}$ and $45^{\circ} \mathrm{C}$ for TRPV1, TRPV1-AD2, TRPV1-AD3, and TRPV1-AD4 chimeras. lonic currents were recorded at $+50 \mathrm{mV}$. Data are given as mean $\pm S D$, with $n \geq 3$ cells. ${ }^{*} p<$ 0.05 obtained with the Student's $t$ test.

mera (TRPV1-AD3) indicated that incorporation of the TRP domain of TRPV3 into TRPV1 shifted the activation energy of channel opening to higher values, without affecting the voltagedependent gating. Similarly, the exchange of this domain affected the temperature sensitivity, but it did not appear to alter the temperature threshold for activation. Together, these findings are consistent with the notion that the TRP domain is neither the voltage nor the temperature sensor, but it rather mediates downstream steps that lead to pore opening. This conclusion is supported by data implying that the voltage sensor may be located in the membrane domain (Voets et al., 2007) and the temperature sensor in the distal half of the C terminus (Vlachova et al., 2003; Brauchi et al., 2006). In addition, the impaired ligand-dependent activation of the most active chimera appears as a result of an alteration of channel gating, as suggested by the significant de- 
crease in the capsaicin-evoked maximal response. This observation is compatible with a model in which the TRP domain contributes to translate the initial binding step into channel opening (Colquhoun, 1998), similar to the role described for the TRP box of TRPM8 (Bandell et al., 2006). Therefore, our findings imply that subunit-subunit interactions in the TRP domain are important for channel gating.

The functional coupling in our chimeras appears to be distorted, probably attributable to an alteration or loss of specific intersubunit interactions present in the TRP domain of wild-type channels. Examination of this region in TRPVs shows fair sequence conservation but a variable probability to coiled-coil formation (Fig. 1A). The TRP domain displays a high-to-modest coiled-coil score for TRPV1-TRPV4 channels but not for the more distant species TRPV5 and TRPV6. The most conspicuous differences between TRPV1 and TRPV5/TRPV6 are concentrated in the amino acids at the core "a" and " $\mathrm{d}$ " positions of the coil. In TRPV1, these positions are occupied by large hydrophobic amino acids, whereas in TRPV5/TRPV6, there is a high propensity of alanine and valine, which are rarely found in coiled coils (Lupas and Gruber, 2005). Accordingly, these positions of the coiled coil could to be important for efficient functional coupling. However, other positions of the TRP domain should play a role in functional coupling, as suggested by severe uncoupling exhibited by the TRPV1-AD2 chimera. This finding was unexpected because the TRP domain of the TRPV2 channel shows a significant amino acid identity with that of TRPV1. Inspection of the amino acid sequences reveals the highest sequence divergence between both regions is located at the $\mathrm{C}$ end of the domain in which the TRPV2 lacks at least three amino acids (Fig. 1). Thus, this chimeric channel provides a molecular scaffold that may facilitate unveiling the structural basis of the functional uncoupling exhibited by these chimeras to the different activating stimuli.

We proposed previously a molecular model for the $\mathrm{C}$ terminus of TRPV1 using the crystallographic coordinates of the cognate domain of $\mathrm{HCN} 2$ as a realistic structural scaffold of the distal C-end half, because of their fairly conserved pattern of secondary structural elements (Cortes et al., 2001; Zagotta et al., 2003; Garcia-Sanz et al., 2004). The TRP domain was represented as a four helix bundle. We have modeled this domain using as a scaffold a tetrameric four-helix bundle (Yadav et al., 2006) that exhibits a similar distribution of Ile at the "a" position of the coiled coil. The model consisted of a helical segment encompassing the entire TRP domain, followed by a binding domain, holding the calmodulin and phosphatidylinositol-4, 5-biphosphate binding sites. The TRP domain brought together the subunits in the homotetramer and defined most of the subunit-subunit interactions. Examination of the four-helix bundle shows that the core "a" and "d" positions of the coil mediate most of the intersubunit interactions. Thus, incorporation of amino acids that disrupt or alter these interactions should have an important impact on the activation energy of channel gating. This notion is substantiated by the lack of activity of heteromers composed of TRPV1 and nonfunctional chimeras. Furthermore, the complete exchange of the $\mathrm{C}$ ends between TRPV1 and TRPM8 gave rise to active chimeras that conserved the functional properties of the respective cytosolic domains, namely temperature sensitivity and modulation by phosphoinositides (Brauchi et al., 2006). Interestingly, in TRPM8, the corresponding TRP domain was involved the modulation of functional aspects (Rohacs et al., 2005) but not in subunit oligomerization that was mediated by a coiled-coil region located in the distal C end (Erler et al., 2006; Tsuruda et al.,
2006). Therefore, preservation of compatible intersubunit and intrasubunit interactions in the TRP domain appears critical for functional coupling. It is interesting to note that core of the coiled coil encompasses the highly conserved segment known as the TRP box (Clapham, 2003), whose function remains elusive. Our findings hint to an important role of this segment in the coupling the conformational change induced by the activating stimulus to gate opening. Ongoing experiments in our laboratory are addressing this question.

The central question that emerges is, how does the TRP domain contributes to channel gating? Although the mechanism by which this region influences activation is unknown in other channels (Paoletti et al., 1999), our results suggest that this protein region may operate as a negative allosteric modulator of channel opening, working as a coiled-coil zipper that holds the channel in the closed state. The energy released on stimuli sensing could remove this inhibition, thus allowing the gating process. The conformational changes induced by the activating stimulus could be coupled to the channel gate through a structural change of the TRP domain that alters the subunit interface between neighboring subunits. Thermodynamics studies reveal that channel gating is associated with a large increase of both the enthalpy $(\sim 150$ $\mathrm{kcal} / \mathrm{mol})$ and the entropy $\left(\sim 470 \mathrm{cal} / \mathrm{mol}^{\circ} \mathrm{K}\right)$ (Nilius et al., 2005). These high values are in agreement with the thermodynamic stability of tetrameric coiled coils that also involved large enthalpic and entropic changes during denaturation (Lupas and Gruber, 2005). Accordingly, partial unfolding of the coiled-coil structure, triggered by the stimulus-driven conformational change, could have an impact on subunit packing that, ultimately, would be transduced into opening of the channel gate. This putative mechanism is consistent with the higher order (lower entropy) of the closed state of the channel. Therefore, a coiled-coil structure for the TRP domain appears to be compatible with the thermodynamics of channel gating.

In conclusion, the location of the TRP domain just after the inner pore helix that structures the channel gate is consistent with a dual functionality, operating as a tetramerization domain that stabilizes channel subunits and also a as transduction domain that couples stimuli sensing to channel gating. Intersubunit and intrasubunit interactions within this segment seem to contribute to the setting of the activation threshold of channel opening. Additional structure-function experiments are necessary to understand the molecular mechanism underlying the functional role of this protein domain.

\section{References}

Arniges M, Fernandez-Fernandez JM, Albrecht N, Schaefer M, Valverde MA (2006) Human TRPV4 channel splice variants revealed a key role of ankyrin domains in multimerization and trafficking. J Biol Chem 281:1580-1586.

Bandell M, Dubin AE, Petrus MJ, Orth A, Mathur J, Hwang SW, Patapoutian A (2006) High-throughput random mutagenesis screen reveals TRPM8 residues specifically required for activation by menthol. Nat Neurosci 9:493-500.

Brauchi S, Orio P, Latorre R (2004) Clues to understanding cold sensation: thermodynamics and electrophysiological analysis of the cold receptor TRPM8. Proc Natl Acad Sci USA 101:15494-15499.

Brauchi S, Orta G, Salazar M, Rosenmann E, Latorre R (2006) A hot-sensing cold receptor: C-terminal domain determines thermosensation in transient receptor potential channels. J Neurosci 26:4835-4840.

Caprini M, Fava M, Valente P, Fernandez-Ballester G, Rapisarda C, Ferroni S, Ferrer-Montiel A (2005) Molecular compatibility of the channel gate and the $\mathrm{N}$ terminus of S5 segment for voltage-gated channel activity. J Biol Chem 280:18253-18264.

Caterina MJ, Julius D (2001) The vanilloid receptor: a molecular gateway to the pain pathway. Annu Rev Neurosci 24:487-517. 
Chang Q, Gyftogianni E, van de Graaf SF, Hoefs S, Weidema FA, Bindels RJ, Hoenderop JG (2004) Molecular determinants in TRPV5 channel assembly. J Biol Chem 279:54304-54311.

Chung MK, Lee H, Caterina MJ (2003) Warm temperatures activate TRPV4 in mouse 308 keratinocytes. J Biol Chem 278:32037-32046.

Clapham DE (2003) TRP channels as cellular sensors. Nature 426:517-524.

Colquhoun D (1998) Binding, gating, affinity and efficacy: the interpretation of structure-activity relationships for agonists and the effects of mutating receptors. Br J Pharmacol 125:923-947.

Cortes DM, Cuello LG, Perozo E (2001) Molecular architecture of fulllength KcsA: role of cytoplasmic domains in ion permeation and activation gating. J Gen Physiol 117:165-180.

Dhaka A, Viswanath V, Patapoutian A (2006) TRP ion channels and temperature sensation. Annu Rev Neurosci 29:135-161.

Erler I, Hirnet D, Wissenbach U, Flockerzi V, Niemeyer BA (2004) $\mathrm{Ca}^{2+}$. selective transient receptor potential $\mathrm{V}$ channel architecture and function require a specific ankyrin repeat. J Biol Chem 279:34456-34463.

Erler I, Al-Ansary DM, Wissenbach U, Wagner TF, Flockerzi V, Niemeyer BA (2006) Trafficking and assembly of the cold-sensitive TRPM8 channel. J Biol Chem 281:38396-38404.

Ferrer-Montiel AV, Montal M (1999) Engineering the NMDA receptor channel lining. Methods Mol Biol 128:167-178.

Garcia-Martinez C, Morenilla-Palao C, Planells-Cases R, Merino JM, FerrerMontiel A (2000) Identification of an aspartic residue in the P-loop of the vanilloid receptor that modulates pore properties. J Biol Chem 275:32552-32558.

Garcia-Martinez C, Fernandez-Carvajal A, Valenzuela B, Gomis A, Van Den NW, Ferroni S, Carreno C, Belmonte C, Ferrer-Montiel A (2006) Design and characterization of a noncompetitive antagonist of the transient receptor potential vanilloid subunit 1 channel with in vivo analgesic and anti-inflammatory activity. J Pain 7:735-746.

Garcia-Sanz N, Fernandez-Carvajal A, Morenilla-Palao C, Planells-Cases R, Fajardo-Sanchez E, Fernandez-Ballester G, Ferrer-Montiel A (2004) Identification of a tetramerization domain in the $\mathrm{C}$ terminus of the vanilloid receptor. J Neurosci 24:5307-5314.

Guler AD, Lee H, Iida T, Shimizu I, Tominaga M, Caterina M (2002) Heatevoked activation of the ion channel, TRPV4. J Neurosci 22:6408-6414.

Hellwig N, Albrecht N, Harteneck C, Schultz G, Schaefer M (2005) Homoand heteromeric assembly of TRPV channel subunits. J Cell Sci 118:917-928.

Hoenderop JG, Voets T, Hoefs S, Weidema F, Prenen J, Nilius B, Bindels RJ (2003) Homo- and heterotetrameric architecture of the epithelial $\mathrm{Ca} 2+$ channels TRPV5 and TRPV6. EMBO J 22:776-785.

Jin X, Touhey J, Gaudet R (2006) Structure of the N-terminal ankyrin repeat domain of the TRPV2 ion channel. J Biol Chem 281:25006-25010.

Jung J, Lee SY, Hwang SW, Cho H, Shin J, Kang YS, Kim S, Oh U (2002) Agonist recognition sites in the cytosolic tails of vanilloid receptor 1 . J Biol Chem 277:44448-44454.

Kedei N, Szabo T, Lile JD, Treanor JJ, Olah Z, Iadarola MJ, Blumberg PM (2001) Analysis of the native quaternary structure of vanilloid receptor 1. J Biol Chem 276:28613-28619.

Liedtke W (2005) TRPV4 plays an evolutionary conserved role in the transduction of osmotic and mechanical stimuli in live animals. J Physiol (Lond) 567:53-58.

Liu B, Hui K, Qin F (2003) Thermodynamics of heat activation of single capsaicin ion channels VR1. Biophys J 85:2988-3006.

Lupas AN, Gruber M (2005) The structure of alpha-helical coiled coils. Adv Protein Chem 70:37-78.

McCleverty CJ, Koesema E, Patapoutian A, Lesley SA, Kreusch A (2006) Crystal structure of the human TRPV2 channel ankyrin repeat domain. Protein Sci 15:2201-2206.

Montell C (2005) The TRP superfamily of cation channels. Sci STKE 2005:re3.

Moqrich A, Hwang SW, Earley TJ, Petrus MJ, Murray AN, Spencer KS, Andahazy M, Story GM, Patapoutian A (2005) Impaired thermosensation in mice lacking TRPV3, a heat and camphor sensor in the skin. Science 307:1468-1472.

Morenilla-Palao C, Planells-Cases R, Garcia-Sanz N, Ferrer-Montiel A (2004) Regulated exocytosis contributes to protein kinase C potentiation of vanilloid receptor activity. J Biol Chem 279:25665-25672.

Nijenhuis T, Hoenderop JG, Bindels RJ (2005) TRPV5 and TRPV6 in Ca ${ }^{2+}$ (re)absorption: regulating $\mathrm{Ca}^{2+}$ entry at the gate. Pflügers Arch 451:181-192.

Nilius B, Talavera K, Owsianik G, Prenen J, Droogmans G, Voets T (2005) Gating of TRP channels: a voltage connection? J Physiol (Lond) 567:35-44.

Nilius B, Owsianik G, Voets T, Peters JA (2007) Transient receptor potential cation channels in disease. Physiol Rev 87:165-217.

Paoletti P, Young EC, Siegelbaum SA (1999) C-Linker of cyclic nucleotidegated channels controls coupling of ligand binding to channel gating. J Gen Physiol 113:17-34.

Planells-Cases R, Garcia-Sanz N, Morenilla-Palao C, Ferrer-Montiel A (2005) Functional aspects and mechanisms of TRPV1 involvement in neurogenic inflammation that leads to thermal hyperalgesia. Pflügers Arch 451:151-159.

Ramsey IS, Delling M, Clapham DE (2006) An introduction to TRP channels. Annu Rev Physiol 68:619-647.

Rohacs T, Nilius B (2007) Regulation of transient receptor potential (TRP) channels by phosphoinositides. Pflügers Arch 455:157-168.

Rohacs T, Lopes CM, Michailidis I, Logothetis DE (2005) PI(4,5)P2 regulates the activation and desensitization of TRPM8 channels through the TRP domain. Nat Neurosci 8:626-634.

Schaefer M (2005) Homo- and heteromeric assembly of TRP channel subunits. Pflügers Arch 451:35-42.

Scholz J, Woolf CJ (2002) Can we conquer pain? Nat Neurosci [Suppl] 5:1062-1067.

Smith GD, Gunthorpe MJ, Kelsell RE, Hayes PD, Reilly P, Facer P, Wright JE, Jerman JC, Walhin JP, Ooi L, Egerton J, Charles KJ, Smart D, Randall AD, Anand P, Davis JB (2002) TRPV3 is a temperature-sensitive vanilloid receptor-like protein. Nature 418:186-190.

Tsuruda PR, Julius D, Minor Jr DL (2006) Coiled coils direct assembly of a cold-activated TRP channel. Neuron 51:201-212.

Vlachova V, Teisinger J, Susankova K, Lyfenko A, Ettrich R, Vyklicky L (2003) Functional role of C-terminal cytoplasmic tail of rat vanilloid receptor 1. J Neurosci 23:1340-1350.

Voets T, Droogmans G, Wissenbach U, Janssens A, Flockerzi V, Nilius B (2004) The principle of temperature-dependent gating in cold- and heatsensitive TRP channels. Nature 430:748-754.

Voets T, Owsianik G, Janssens A, Talavera K, Nilius B (2007) TRPM8 voltage sensor mutants reveal a mechanism for integrating thermal and chemical stimuli. Nat Chem Biol 3:174-182.

Vriens J, Watanabe H, Janssens A, Droogmans G, Voets T, Nilius B (2004) Cell swelling, heat, and chemical agonists use distinct pathways for the activation of the cation channel TRPV4. Proc Natl Acad Sci USA 101:396-401

Watanabe H, Davis JB, Smart D, Jerman JC, Smith GD, Hayes P, Vriens J, Cairns W, Wissenbach U, Prenen J, Flockerzi V, Droogmans G, Benham CD, Nilius B (2002) Activation of TRPV4 channels (hVRL-2/mTRP12) by phorbol derivatives. J Biol Chem 277:13569-13577.

$\mathrm{Xu}$ H, Ramsey IS, Kotecha SA, Moran MM, Chong JA, Lawson D, Ge P, Lilly J, Silos-Santiago I, Xie Y, DiStefano PS, Curtis R, Clapham DE (2002) TRPV3 is a calcium-permeable temperature-sensitive cation channel. Nature 418:181-186.

Yadav MK, Leman LJ, Price DJ, Brooks III CL, Stout CD, Ghadiri MR (2006) Coiled coils at the edge of configurational heterogeneity. Structural analyses of parallel and antiparallel homotetrameric coiled coils reveal configurational sensitivity to a single solvent-exposed amino acid substitution. Biochemistry 45:4463-4473.

Zagotta WN, Olivier NB, Black KD, Young EC, Olson R, Gouaux E (2003) Structural basis for modulation and agonist specificity of $\mathrm{HCN}$ pacemaker channels. Nature 425:200-205. 